\title{
Danish guidelines on environmental low frequency noise, infrasound and vibration
}

\author{
Jorgen Jakobsen \\ Danish Environmental Protection Agency, Industrial Section, Strandgade 29, DK - I40I \\ Copenhagen K, Denmark
}

Received 2 March 2001

\begin{abstract}
SUMMARY
In Denmark a set of guidelines for measurement and assessment of environmental low frequency noise, infrasound and vibration was published in 1997 as "Information from the Danish Environmental Protection Agency no. 9/1997" (Miljøstyrelsen ${ }^{2}$ ). Recommended measurement methods are specified, and recommended limit values for noise and vibration are given. In this paper a brief description of the measurement methods is given, the recommended limit values are shown, and the background for the measurement and assessment methods is discussed. This paper is an extended summary of "Information from the Danish Environmental Protection Agency No.9/1997" (in Danish)
\end{abstract}

\section{INTRODUCTION}

Denmark has had recommended limit values for environmental noise since 1974, when the first guidelines for assessing industrial noise were published. These limits are given as A-weighted levels only, and they do not specifically consider low frequency noise. In the 1984 edition of the guidelines, a warning was given against a direct application of the limit values to cases with low frequency noise, as the annoyance would then be underestimated. However no recommended assessment method for low frequency noise could be given at that time.

When general knowledge on hearing in the low frequency region had improved, and drafts or suggestions for assessment methods for low frequency noise were published (Piorr and Wietlake ${ }^{7}$; Vercammen ${ }^{11,12}$ ), it was considered that there was an adequate background for a recommended assessment method to be published. It was realised that knowledge on this topic was not complete and that not all questions could be fully answered. But it would be unacceptable if the existing knowledge was not exploited and made accessible to the authorities and the laboratories dealing with problems due to low frequency noise.

Guidelines for the assessment of environmental vibration were published in Denmark in 1983. These guidelines were updated and were published jointly with the guidelines for low frequency noise and infrasound.

\section{BACKGROUND AND ASSUMPTIONS, NOISE}

Infrasound is sound with frequencies lower than $20 \mathrm{~Hz}$. It is well established that infrasound can be heard (or felt) provided it is loud enough, and a hearing threshold can be determined. There is some conformity between the average thresholds found in different investigations in the literature, as is illustrated in Figure 1.

Also the loudness of infrasound has been investigated (Møller and Andresen ${ }^{4}$ ). It was found that the loudness increased extremely rapidly with increasing sound level above the hearing threshold. The loudness would increase by 40 Phons from a level increase of only about $10 \mathrm{~dB}$ at frequencies 2 and $4 \mathrm{~Hz}$. In Møller ${ }^{3}$ it was shown that also the annoyance from audible infrasound increased very rapidly with 


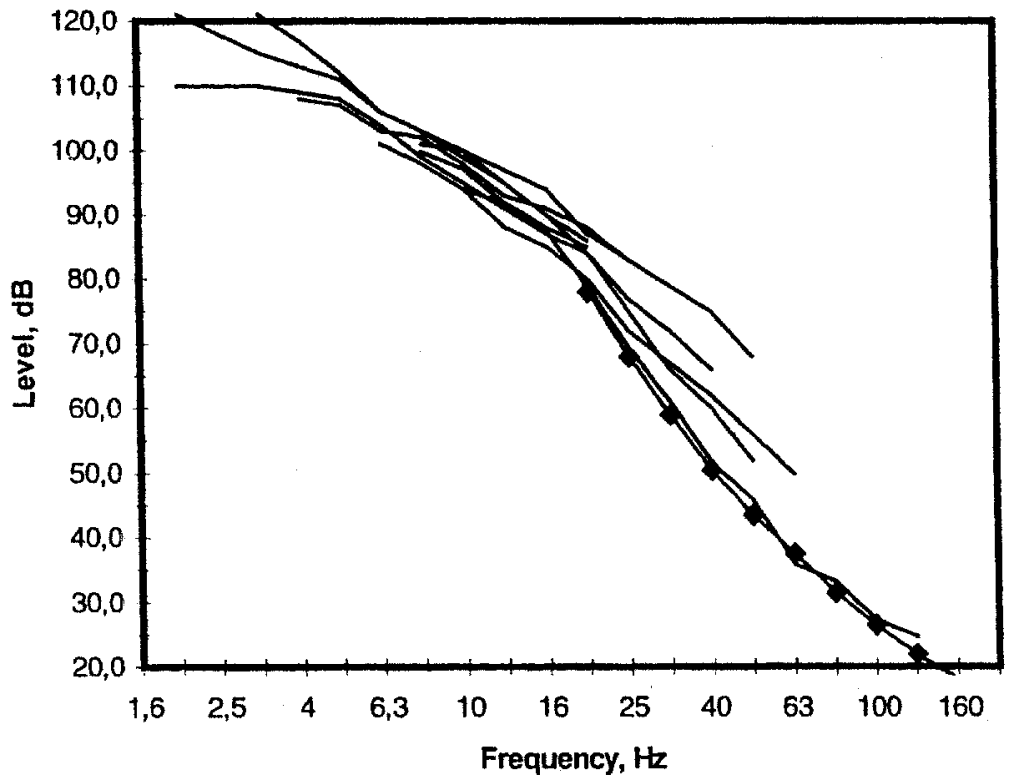

Figure I. Examples of hearing thresholds. The standardised hearing threshold (ISO 389-7) is shown with diamond symbols

increasing sound level, and it was found that there is a close relation between the G-weighted level of the infrasound and the annoyance sensation.

It is assumed that infrasound that cannot be heard is not annoying, and it is believed that it has no other adverse or health effects. It is also assumed that infrasound only slightly above the hearing threshold may be annoying. The average hearing threshold for infrasound corresponds to tones each having a G-weighted level of approximately $\mathrm{L}_{\mathrm{pG}}=96 \mathrm{~dB}$.

In the lowest region of the frequency range above $20 \mathrm{~Hz}$, a simple inspection of the standardised equal loudness contours reveal that at the lowest frequencies $(20-$ $50 \mathrm{~Hz}$ ) the loudness increases much more with increasing level than at higher frequencies, see Figure 2. When the sound pressure level in this region increases by $20 \mathrm{~dB}$, the loudness increases almost 40 Phons, while this level increase at $1000 \mathrm{~Hz}$ will increase the loudness by 20 Phons - by definition. Thus the so-called 'narrowing of the dynamic range' is less that it is in the infrasound region. It would

\section{Normal Equal Loudness Contours for pure tones}

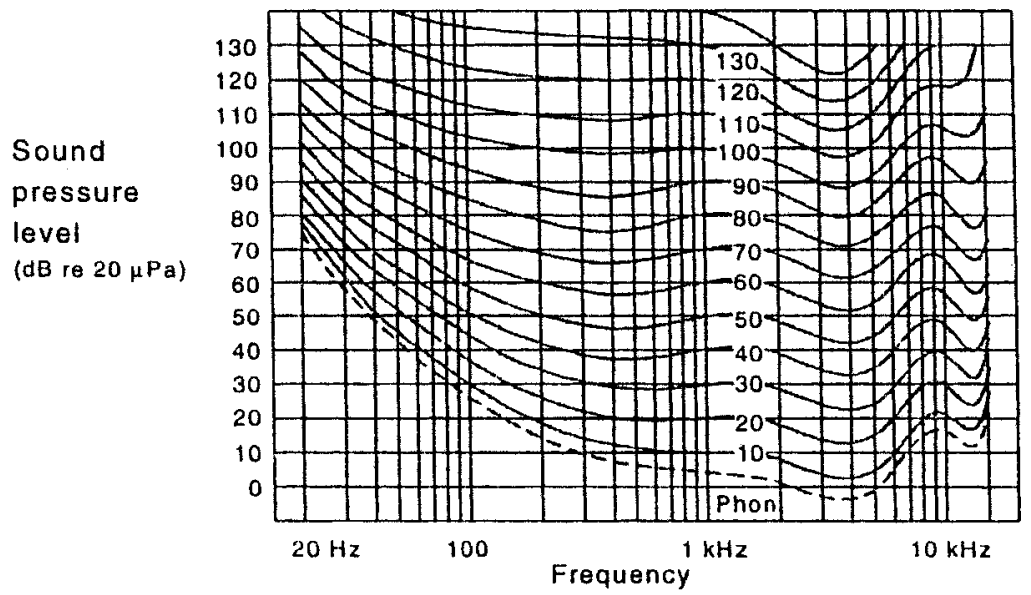

Figure 2.

Standardised Equal Loudness Contours from ISO 226. (Reproduced from Brüel \& Kjær lecture notes "Psychoacoustics - a qualitative description" BA 7615-13) 
appear that the frequency range $20-$ about $150 \mathrm{~Hz}$ can be regarded as a transition zone between the infrasound region and the middle frequencies.

The A-weighting filter was originally defined as a 'best fit' to the shape of the equal loudness contours at low levels. A closer inspection reveals that the Aweighting filter overestimates the loudness at low levels at the lowest frequencies. This is also true for the proposed revision of equal loudness contours (Møller and Lydolf ${ }^{5}$ ). Thus it can be expected that the use of the A-weighting corrections specifically in the low frequency region would be advantageous in giving a more strict assessment at the lowest frequencies in this region

This does not imply that the A-weighted noise level (of the entire frequency range) in itself will give a good measure of the loudness or even the annoyance of noise with a low frequency content. On the contrary it is a frequent observation that the A-weighted noise level underestimates the annoyance of low frequency noise, which may possibly be caused by the above mentioned 'narrowing of the dynamic range'.

Most of the measurements of the hearing threshold and other investigations on hearing in the low frequency region are made with single tones or narrowband noise. There is no established method for evaluating broadband low frequency noise or low frequency noise consisting of several tones. It can be taken as a secure assumption that the concept of loudness summation within a critical band also is valid at low frequencies and in the infrasound range, and that the entire frequency region from ca. $1 \mathrm{~Hz}$ to approx. $150 \mathrm{~Hz}$ can be regarded as one critical band.

An assessment method based on this concept would call for a sound level dependent weighting function in the entire region that will consider the extreme steepness of the loudness vs. noise level dependence in the infrasound range. Neither generally accepted weighting functions nor the level dependent filters exist, so a simpler procedure will have to be followed.

It is natural to use the standardised G-weighting function (ISO 7196) for an assessment of infrasound. The G-weighting however has a sharp cut-off at $20 \mathrm{~Hz}$ and is not intended for use at higher frequencies. This feature may result in an underestimation of loudness at frequencies between about 16 and $20 \mathrm{~Hz}$. The Aweighting function may be used to assess the noise in the low frequency range up to about $150 \mathrm{~Hz}$. It is necessary to limit the frequency range by a low-pass filter to avoid a mixed evaluation of low frequency noise and noise at middle frequencies. The low frequency noise is assessed by the use of a set of criteria separately from the criteria used with the overall A-weighted noise level. To overcome the possible underestimation for the frequency range $16-20 \mathrm{~Hz}$, the A-weighting is used down to $10 \mathrm{~Hz}$. Due to the excessive tolerances at low frequencies on the A-weighting filter in the instrumentation standard (IEC 651), the A-weighted level of the low frequency noise cannot be measured with a normal sound level meter supplied with a low pass filter. The level instead must be synthesised from a narrowband frequency analysis by addition of the nominal weighting function.

It is sometimes suggested to use the C-weighted noise level for an assessment of low frequency noise. This is not encouraged, as there is a poor relation between the $\mathrm{C}$-weighting function and the shape of the equal-loudness contours at low frequencies and low levels.

\section{RECOMMENDED NOISE LIMITS}

An environmentally acceptable infrasound level must be below the hearing threshold. It can be assumed that the individual hearing threshold may be $10 \mathrm{~dB}$ lower than the average threshold, so the recommended limit for environmental infrasound must be $\mathrm{L}_{\mathrm{pG}}=85 \mathrm{~dB}$.

For the low frequency noise the A-weighted level of the noise in the frequency range $10-160 \mathrm{~Hz}$ is regarded, the symbol used is $\mathrm{L}_{\mathrm{pA}, \mathrm{LF}}$. The recommended limits are $5-15 \mathrm{~dB}$ lower than the ordinary noise limits, and the lowest recommended limit $\mathrm{L}_{\mathrm{pA}, \mathrm{LF}}=20 \mathrm{~dB}$ has a close connection with the infrasound limit $\mathrm{L}_{\mathrm{pG}}=85 \mathrm{~dB}$ as illustrated in Figure 3. 
Table $I$. Recommended limits for infrasound $\left(L_{p G}\right)$, for low frequency noise ( $\left.\mathrm{L}_{\mathrm{pA}, \mathrm{LF}}\right)$, and the usual noise limit for noise from enterprises ( $\mathrm{L}_{\mathrm{pA}}$ used when the enterprise and the dwelling is in the same building). All levels in $\mathrm{dB}$ re $20 \mu \mathrm{Pa}$

\begin{tabular}{lccc} 
& Infrasound, $\mathrm{L}_{\mathrm{pG}}$ & Low frequency noise, $\mathrm{L}_{\mathrm{pA}}, \mathrm{LF}$ & Usual noise limit, $\mathrm{L}_{\mathrm{pA}}$ \\
\hline Dwelling, evening \& night & $85 \mathrm{~dB}$ & $20 \mathrm{~dB}$ & $30 \mathrm{~dB} / 25 \mathrm{~dB}$ \\
Dwelling, day & $85 \mathrm{~dB}$ & $25 \mathrm{~dB}$ & $30 \mathrm{~dB}$ (day \& evening) \\
Classroom, office etc. & $85 \mathrm{~dB}$ & $30 \mathrm{~dB}$ & $40 \mathrm{~dB}$ \\
Other rooms in enterprises & $90 \mathrm{~dB}$ & $35 \mathrm{~dB}$ & $50 \mathrm{~dB}$
\end{tabular}

The noise limits are compared to the sound levels measured over a reference time period of 10 minutes; the usual noise limits in force are however used with reference time periods of 8 hours, 1 hour and $1 / 2$ hour for the day, the evening, and the night period respectively. If the noise is impulsive, e.g. from single blows with a press or a forging hammer, the recommended limits are reduced by $5 \mathrm{~dB}$.

\section{NOISE MEASURING METHOD}

Normally measurement of environmental noise takes place outdoors. This is not possible with low frequency noise partly due to the disturbance from even light wind, partly because an outdoor measurement will not consider re-radiated structure borne noise. Furthermore it is a frequent observation that low frequency noise is considered more annoying indoors.

The recommended noise measurement method was adapted from a recent Swedish measurement method $\left(\mathrm{SP}^{9}\right)$ to fulfil the following demands:

- $\quad$ it shall give precise and reproducible results, enabling, inter alia, a meaningful control measurement after noise abatement has been made.

- it shall give reliable and representative results that represent typical high sound levels experienced by the occupants.

- $\quad$ it shall be simple and feasible for the noise laboratories using normal sound measurement equipment, so that it will be used in practice and the costs will not be excessive.

When the noise level is measured in only one position in a room, there is a vast uncertainty on the result because the noise level differs considerably from one point to another. With tonal noise this is very pronounced due to standing waves, giving a pattern of narrow very deep minima of the noise level. Differences above $30 \mathrm{~dB}$

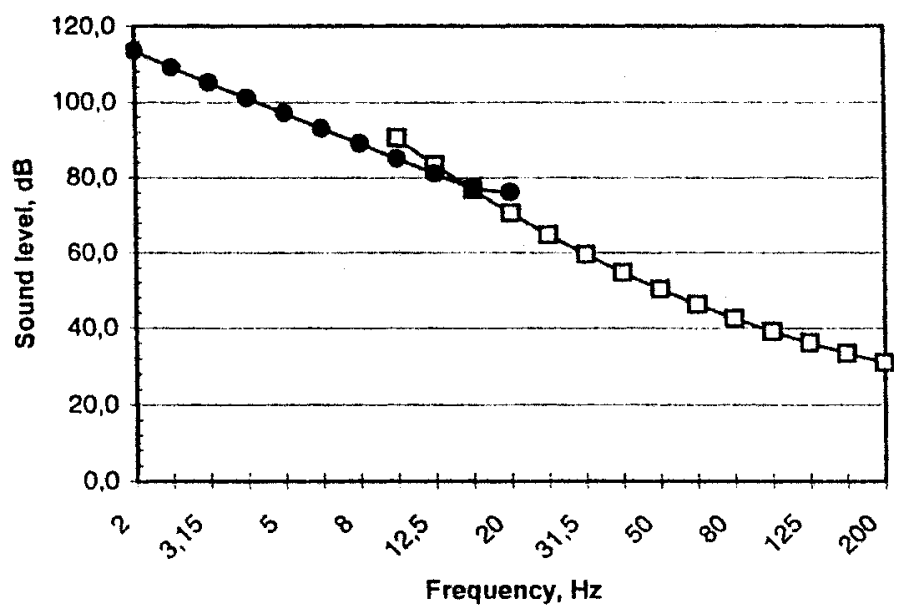

Figure 3. Curves showing the sound levels of tones each giving an infrasound level of $L_{p G}=85 d B$ or an A-weighted level of $L_{p A}=20 \mathrm{~dB}$, both levels re $20 \mu \mathrm{Pa}$ 
are seen in practice. In general a "characteristic point" in a dwelling where a representative noise measurement can be made sufficiently precise cannot be defined. It has been suggested to measure the noise level in a corner, as the noise level is often higher here than in other points in the room. This generally holds well for higher frequencies, but investigations have shown that the infrasound level can be as much as $10 \mathrm{~dB}$ lower in a corner than in other points in the room.

The measurement method specifies that the noise normally shall be measured in at least 3 points in each room. One point is chosen near a corner, $0.5-1 \mathrm{~m}$ from the adjoining walls and $1-1.5 \mathrm{~m}$ above the floor. The other points are chosen so they represent normal positions in the room, at least $0.5 \mathrm{~m}$ from walls and large pieces of furniture and $1-1.5 \mathrm{~m}$ above the floor. Often the occupants can identify points where the noise is highest, and it is important to measure in these points. If they cannot, the technician must choose measuring points according to his own judgement; however points near the midpoint of the room shall be avoided as the noise level often is lowest here. In small rooms (less than about $20 \mathrm{~m}^{2}$, the noise can be measured in two points in different corners $0.5-1 \mathrm{~m}$ from the adjoining walls and $1-1.5 \mathrm{~m}$ above the floor.

The noise is measured in the room in the dwelling where the occupant states that the noise is highest; supplementary measurements can be made in other rooms (sleeping rooms or living rooms).

The operating conditions of the noise source shall be representative for the situation that is complained about, and the background noise shall be as low as possible. Windows and doors shall be closed; if it is claimed that the low frequency noise is stronger with open windows a supplementary measurement can then be made. If possible the background noise is measured with the noise source stopped. This also identifies which source is responsible for which part of the noise.

Narrowband analyses are made of the noise from each measurement point. Normally the noise levels will have to be averaged over at least 5 minutes to average out random fluctuations due to sound propagation. If the noise source is varying, the analysis interval shall equal the reference time interval of 10 minutes. When it has been possible to measure the background noise, the spectra are corrected for background noise. The measured (and corrected) spectra are added to the nominal G- and A-weighting corrections. By summation the infrasound level (of the noise in the frequency range from $2-5 \mathrm{~Hz}$ up to $20 \mathrm{~Hz}$, usually the frequency components below about $5 \mathrm{~Hz}$ have no influence on the G-weighted level) and the A-weighted level of the noise in the range $10-160 \mathrm{~Hz}$ is calculated. The energy average of the G- and the A-weighted noise level from all the measurement points in the same room is calculated and is compared to the recommended noise limits.

\section{BACKGROUND AND ASSUMPTIONS, VIBRATION}

Vibrations in the environment are usually considered annoying at a level that is only slightly above the sensation threshold. This assumption has been the basis for the Danish guidelines on vibration since 1983. The vibration level is measured as a broadband level that is weighted with a well-defined function. For vibration the standardised "whole body combined" weighting is used, also called "KBweighting". This weighting is a simple low-pass filtering of the acceleration signal below $5.7 \mathrm{~Hz}$; in addition a frequency limiting to the range $1-80 \mathrm{~Hz}$ is prescribed. Vibrations are measured on the floor. The maximum level is used as a basis for the assessment. For stationary vibration sources there is no difference between the maximum and the average level, however most of the experience in this topic concerns vibration from railways or from construction activities.

In 1991 a Nordtest ${ }^{6}$ method was published, based on the experience with, inter alia, the Danish guidelines. This method gives measurements with better accuracy in specifying more measurement points. Also the international standardisation on this topic has moved; at present the draft for a revised ISO 2631-2 "Vibration in buildings $(1-80 \mathrm{~Hz})$ "' is on vote. 


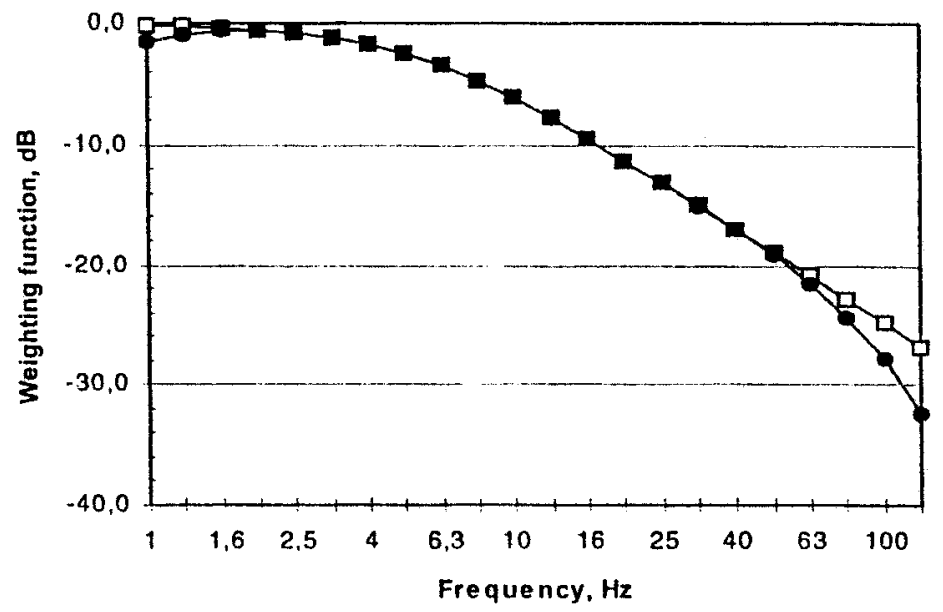

Figure 4. Whole-body combined weighting function shown both with and without band limiting to $\mathrm{I}-80 \mathrm{~Hz}$

When setting limits that reflect environmentally acceptable vibration levels, only tactile vibration is considered. Re-radiated noise that often accompanies vibration is assessed as low frequency noise. Secondary phenomena such as rattling windows or pieces of furniture are not considered. Questions of possible building damage that often worry occupants are not taken into account when setting the recommended limit values. It should be noted that the criteria traditionally used for assessment of possible damage are much higher than the 'comfort criteria'.

\section{MEASUREMENT AND ASSESSMENT OF VIBRATION}

Vibrations are measured in the room where the occupants experience them to be strongest. According to his judgement the technician can measure in other rooms too. Measurements are made at that point and that direction where the highest level is expected. With typical Danish buildings this is the vertical direction, and in buildings with two or more storeys the level usually is higher on the upper storey. The highest level is expected on the midpoint of the floor with the longest free span. Supplementary measurements are made in $1-2$ points at least $1 \mathrm{~m}$ from the primary measurement point and from the walls. The transducer (accelerometer) shall have firm contact with the floor. If the floor is carpeted, a probe that penetrates the carpet can be used for measurement of vertical vibration. On lightweight (floating) floors the measured level depends on the loading of the floor. For that reason the floor should be loaded by a person who sits quietly on a chair near the measurement point. The use of weights is not encouraged.

The signal from the transducer is frequency weighted, and the time dependent weighted acceleration level is recorded. Time weighting constant $\mathrm{S}$ (slow) is used; as a close approximation a running RMS with integration interval $2 \mathrm{~s}$ can also be used (this is specified in the recent draft for ISO 2631-2). The energy average of the maximum levels that occur simultaneously in the ( 2 or more ) measuring points is calculated and is compared to the recommended vibration limits (Table II).

For comparison with the recommended vibration limits it can be mentioned that the threshold of sensation is about $72 \mathrm{~dB}\left(\right.$ re $\left.10^{-6} \mathrm{~m} / \mathrm{s}^{2}\right)$ or $4 \mathrm{~mm} / \mathrm{s}^{2}$.

\section{COMPARISON TO OTHER GUIDELINES}

Procedures and guidelines for assessment of environmental low frequency noise have recently been published in, inter alia, Sweden, Germany, and The Netherlands (Socialstyrelsen $^{8}, \mathrm{DIN}^{1}$, Stichting Geluidhinder ${ }^{10}$ ). It is relevant to compare the Danish recommended assessment method with these methods, although this is difficult to do precisely because the assessment methods and the corresponding measurement methods differ. 


\section{Table II. Recommended limits for vibration, given both as the weighted acceleration level in $\mathrm{dB}$ re $10^{-6} \mathrm{~m} / \mathrm{s}^{2}$, weighted vibration $\left(\mathrm{mm} / \mathrm{s}^{2}\right)$, and the corresponding weighted velocity $(\mathrm{mm} / \mathrm{s})$}

\begin{tabular}{lccc} 
& $\begin{array}{c}\text { Weighted acceleration } \\
\text { level, } \mathrm{L}_{\mathrm{aw}}\end{array}$ & $\begin{array}{c}\mathrm{a}_{\mathrm{w}} \\
\text { Weighted acceleration }\end{array}$ & $\begin{array}{c}\text { Corresponding } \\
\text { weighted velocity } \mathrm{v}_{\mathrm{w}}\end{array}$ \\
\hline $\begin{array}{l}\text { Dwelling in residential areas (day and night) or } \\
\text { In mixed areas (evening \& night), institution }\end{array}$ & $75 \mathrm{~dB}$ & $5.6 \mathrm{~mm} / \mathrm{s}^{2}$ & $0.16 \mathrm{~mm} / \mathrm{s}$ \\
\hline $\begin{array}{l}\text { Dwelling in mixed areas (day), office and } \\
\text { classroom }\end{array}$ & $80 \mathrm{~dB}$ & $10 \mathrm{~mm} / \mathrm{s}^{2}$ & $0.3 \mathrm{~mm} / \mathrm{s}$ \\
\hline Other rooms in enterprises & $85 \mathrm{~dB}$ & $17.8 \mathrm{~mm} / \mathrm{s}^{2}$ & $0.5 \mathrm{~mm} / \mathrm{s}$
\end{tabular}

The German standardised method distinguishes between tonal noise and broadband noise. For broadband noise the recommended limits are $25 \mathrm{~dB}$ at night and $35 \mathrm{~dB}$ by day (A-weighted levels in the frequency range $10-80 \mathrm{~Hz}$ ). For tonal noise the tone level must not exceed a 'threshold' that corresponds to an Aweighted level of between $25 \mathrm{~dB}$ (at $20 \mathrm{~Hz}$ ) and $6 \mathrm{~dB}$ (at $80 \mathrm{~Hz}$ ). At $80 \mathrm{~Hz}$ however an exceedence of up to $5 \mathrm{~dB}$ is allowed. The Swedish and the Dutch assessment methods also specify a 'threshold' that must not be exceeded. The Swedish method deals with the range $31.5-200 \mathrm{~Hz}$, while the Dutch concentrates on $20-100 \mathrm{~Hz}$. The Dutch 'threshold' corresponds closely to the German, but no relaxation is allowed at higher frequencies. The Swedish threshold corresponds to the German threshold at the lowest frequencies, and to an A-weighted level of approx. $20 \mathrm{~dB}$ at frequencies above approx. $100 \mathrm{~Hz}$.

If the low frequency noise consists of one tone only, the Danish assessment method is the most strict at frequencies below $25 \mathrm{~Hz}$. In the interval $40-50 \mathrm{~Hz}$ the other methods roughly give the same assessment, which is some $\mathrm{dB}$ stricter than the Danish. At higher frequencies the German and the Dutch methods deviate and give significantly stricter assessments than both the Danish and the Swedish methods. If the noise consists of more tones or broadband noise, the Danish assessment method will take the possible loudness summation into account and assess this more strictly, while the three other methods only consider the 'loudest' of the narrowband levels.

A comparison of recommended vibration limits has recently been made within the framework of a revision of ISO 2631-2. A questionnaire was made where the countries should indicate their 'guidance values above which adverse comments due to building vibration could occur'. Even if such a comparison must be regarded with precaution, as many important parameters are not considered, some guidance can be taken from it. It was found that the Danish recommended vibration limits were among the lowest.

\section{REFERENCES}

1 DIN (1997): DIN 45680 "Messung und Bewertung tieffrequenter Geräuschimmissionen in der Nachbarschaft" + Beiblatt: "Hinweise zur Beurteilung bei Gewerblichen Anlagen" (in German)

2 Miljøstyrelsen (1997) Information no. 9/1997 from the Danish Environmental Protection Agency: "Orientering om lavfrekvent støj, infralyd og vibrationer i eksternt miljø" (in Danish)

3 Møller, H. (1987), “Annoyance of Audible Infrasound”, J. Low Freq. Noise Vib. 6 , p. $1-17$.

4 Møller, H. and Andresen, J. (1984), "Loudness of pure tones at low and infrasonic frequencies", J. Low Freq. Noise Vib. 3, p. $78-87$. 
5 Møller, H and Lydolf, M. (1997) "On the use of A-weighted level for prediction of loudness level". Proceedings of the 8th International Conference on Low Frequency Noise and Vibration, Gothenburg 1997, p.197 - 206.

6 Nordtest (1991) Nordtest Method NT ACOU 082: "Buildings: Vibration and shock, evaluation of annoyance"

7 Piorr, D. and Wietlake, K.H. (1989). "Assessment of low frequency noise in the vicinity of industrial noise sources". Proceedings of the 5th International Conference on Low Frequency Noise and Vibration, Oxford 1989, p.61-67.

8 Socialstyrelsen (1996): General guidelines issued by the Swedish National Board of Health and Welfare, SOSFS 1996:7/E "Indoor Noise and High Sound-Levels", adopted 15th May 1996.

9 SP (1996) The Swedish Testing and Research Institute SP-Report 1996:10 "Measurement of low frequency sound in rooms".

10 Stichting Geluidhinder (1999): Nederlandse Stichting Geluidhinder: "Richtlijn Laagfrequent Geluid", Delft 1999 (In Dutch; quoted from: G.P. van den Berg: "Assessment of low frequency noise complaints", Proceedings of InterNoise 1999 p. 1993 - 1996 (Miami 1999).

11 Vercammen, M.L.S. (1989). "Setting limits for Low Frequency Noise”, J. Low Freq. Noise Vib. 2 p. 105- 109.

12 Vercammen, M.L.S. (1992). "Low Frequency Noise Limits", J. Low Freq. Noise Vib. 11 p. $7-13$.

\section{STANDARDS}

IEC 651 'Specification for sound level meters' International Electrotechnical Commission, (1979).

ISO 226 'Specification for normal equal-loudness contours for pure tones under free-field listening conditions', International Organisation for Standardisation, Geneva, Switzerland, (1988)

ISO 389-7 Acoustics Part 7, 'Reference threshold of hearing under free-field and diffuse-field listening conditions' International Organisation for Standardisation, Geneva, Switzerland.

ISO 2631-2 Guide to human exposure to vibration in buildings ( $1 \mathrm{~Hz}$ to $80 \mathrm{~Hz}$ ). International Organisation for Standardisation, Geneva, Switzerland (1989).

ISO 7196 Acoustics, 'Frequency weighting characteristics for infrasound measurement' International Organisation for Standardisation, Geneva, Switzerland. 